\title{
Growth and volume based on permanent sample plots in forests managed by communities
}

\author{
L. Puri ${ }^{1 *}$, H. Meilby ${ }^{2}$, S. Rayamajhi ${ }^{1}$, Y. P. Timilsina ${ }^{1}$, N. P. Gautam ${ }^{1}$, R. Subedi ${ }^{1}$ and \\ H. O. Larsen ${ }^{2}$
}

\begin{abstract}
In order to monitor the woody biomass yield 241 permanent sample plots were established in four forests (total $2017 \mathrm{ha}$ ) across three physiographic regions of Nepal. Tree species identification, tree positioning and diameter at breast height $(\mathrm{DBH})$ for all trees and height for a sample of trees were measured in 2005 and 2010. Results presented are density and volume by forest, species and diameter class in 2010 and the species-wise increment between 2005 and 2010 by forest. Standing volumes were between 134 and $311 \mathrm{~m}^{3} \mathrm{ha}^{-1}$, and annual volume increment was 2.5-7.6 $\mathrm{m}^{3} \mathrm{ha}^{-1}$. These plots may be utilized for future research, teaching and for local planning purposes.
\end{abstract}

Key words: Community forestry, forest growth, stratified sample

$T^{1}$ he Nepalese community forestry programme is internationally well known - it has a long history and it is considered largely successful (Chhetri, 2006). Many studies on community forestry in Nepal have focused on the economic contribution from the forest and aspects related with the distribution of benefits (Adhikari, 2005; Chhetri, 2010), while fewer have looked at forest growth. The general perception is, however, that community forestry succeeds on conserving the forest while allowing local users to extract forest products primarily for subsistence (Pandit and Bevilacqua, 2011). However, the community forestry programme also allows for commercial harvest of forest products, including timber through sustainable forest management.

The Community Based Natural Forest Management in the Himalaya (ComForM) project is a research capacity development programme implemented in collaboration between the Institute of Forestry, Pokhara and Hetauda, Department of Forest Research and Survey, Kathmandu, and plots in four forests under community-based management to monitor the development and use of the University of Copenhagen, Denmark. The project has established a system of permanent sample forest to assess the sustainability of forest management in terms of woody biomass yield. The present paper reports results from plot measurements in 2005 and 2010, including

${ }^{1}$ Tribhuvan University, Institute of Forestry, Pokhara, Nepal.

${ }^{2}$ Forest \& Landscape, University of Copenhagen, 1958 Frederiksberg C, Denmark

* Corresponding author: puri07878@alumni.itc.nl descriptive data from 2010, the most recent situation, and data on the increment between 2005 and 2010. The objective of the paper is to make the plot network known to a wider audience, to inspire similar work elsewhere and to provide baseline data that can be used by future studies.

\section{Materials and methods}

\section{Study sites}

Permanent sample plots were located at the southern edge of the Middle Hills, in the Middle Hills, and in the lower Trans-Himalayan zone representing three physiographic zones of central Nepal. The forests were Kankali community forest $\left(27.65^{\circ} \mathrm{N}, 84.57^{\circ} \mathrm{E}\right)$ in Chainpur Village Development Committee (VDC), Chitwan District, Tibrekot Community Forest $\left(28.29^{\circ} \mathrm{N}\right.$, $83.93^{\circ} \mathrm{E}$ ) in Hemja VDC, Kaski District, and the forests of Lete and Kunjo $\left(28.64^{\circ} \mathrm{N}, 83.62^{\circ} \mathrm{E}\right)$ VDCs, Mustang District in the Annapurna Conservation Area. The dominant vegetation types represented are tropical Shorea robusta forest in Kankali (760 ha), subtropical SchimaCastanopsis forest in Hemja (79 ha) and temperate Pinus wallichiana forest in Lete and Kunjo (501 and 677 ha, respectively).

Plots were allocated to forest strata according to the principles of stratified random sampling described by Meilby et al. (2006). Within each 
stratum, plots were distributed spatially using a principle known as a 'coffee-house' design, which is a restricted random approach where the location of the first plot is totally random and each additional plot is located such that the minimum distance to neighbouring plots is maximized (Müller, 2001). Plots that could not be established at the point initially selected, because this point was inaccessible (precipitous slope, gorge), were moved in steps of 50 metres in a random direction until an accessible point was reached.

Measurements were undertaken in a total of 241 permanent $20 \times 25 \mathrm{~m}$ sample plots in the four forests in the spring of 2005 and repeated in 2010 (Fig.1). Plots were marked using concrete pillars, painted numbers and sign boards but the permanence of these was not in all cases satisfactory. Nevertheless, all plots except one in Kunjo were found again in 2010. Due to the establishment of a Maoist encampment in five plots and the clearing of a Dalbergia sissoo plantation with four plots in Kankali, two new plots were established in that forest and measured for the first time in 2010. Furthermore, one extra plot was established in Tibrekot forest and measured for the first time in 2010.

The basic plot design was based on MFSC (2000) and included three nested levels: trees with a diameter at breast height $(\mathrm{DBH})$ of at least $10 \mathrm{~cm}$ were measured within the whole $20 \times 25 \mathrm{~m}^{2}$ plot, trees with DBH 4-9.9 cm were measured within an interior $10 \times 15 \mathrm{~m}^{2}$ plot, and trees with DBH 2-3.9 cm were measured within an interior $5 \times 5 \mathrm{~m}^{2}$ plot. Parameters measured included species identification, positioning and DBH for all trees. Tree height was measured for a set of panel trees (species- and diameter-stratified; 1258 trees in 2005, 1146 trees in 2010). In 2010 the health and quality was also assessed for these panel trees. Stumps of trees that had disappeared between 2005 and 2010 were registered as felled trees. Crown cover was assessed at 30 points in a regular 5 x $5 \mathrm{~m}$ grid across each plot.

To provide an overview, not only of standing biomass but also its potential value, stand density and volume were estimated for trees in $10 \mathrm{~cm}$ diameter classes. To include estimates of firewood, volume of trees with a diameter lower than $10 \mathrm{~cm}$ was included. Total volume was estimated using volume functions developed by Sharma and Pukkala (1990). Spatial interpolation was carried out using kriging and maps showing the spatial variation of standing volume in 2010 were prepared.

\section{Results and discussion}

For 2005 and 2010 a total of 9603 trees were registered, 7111 were alive in both years, 1023 trees had grown into the sample by reaching the minimum diameter in 2010, and 1412 trees had been harvested in the period between the two measurements. Only seven trees were missing from the database, meaning that their presence was registered but they had not been measured in 2005 or 2010 . Fifty trees that were registered in 2005 were recorded as standing dead trees in 2010.

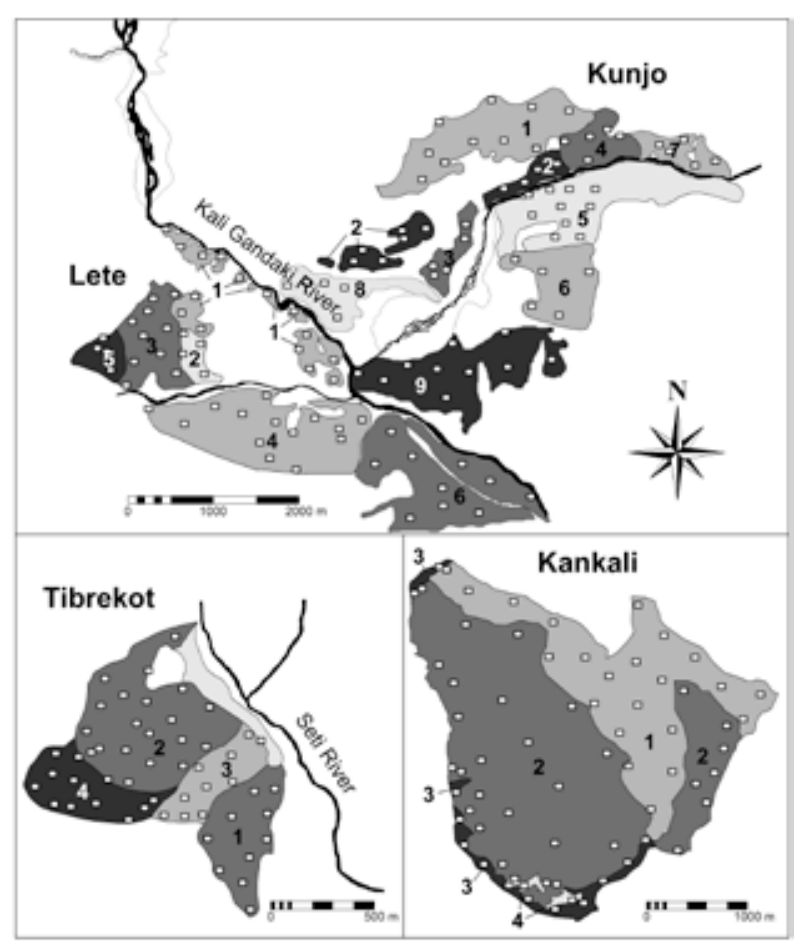

Fig.1: Location of permanent sample plots (rectangular symbols) in the four forests. Stratification is indicated by shading and numbers. For detailed information on the strata please refer to Meilby et al. (2006).

Data describing the state of the forest in 2010 are presented in table 1. Standing volumes were high in Lete and Kunjo VDCs, lower in Tibrekot Community Forest (CF) and even lower in Kankali CF, most of which is young regeneration forest (Stratum 2 in Fig.1) that used to be severely degraded and has regenerated after the establishment of the Community Forest User Group (CFUG) in 1995. Periodic annual volume increment was slightly higher in Kunjo than in 
Lete, presumably because part of the forest in Lete (Strata 2 and 3, Fig. 1) is relatively open, even though this is not indicated by the overall basal area and volume estimates. The estimated volume increment was highest in Kankali, possibly because - as mentioned - most of the forest is very young.

The standard errors (not shown) of $\mathrm{DBH}$ and height are generally $2-7 \%$ of the estimates, those of stem number, basal area and volume are 5-15\%. The standard errors are low for Kunjo, Tibrekot and Kankali, but for Lete they are somewhat higher due to the large variation of the forest around Lete with strata characterised as open pine forest, dense pine forest, degraded pine and Tsuga, Rhododendron forest, and dense oldgrowth forest with very large old Tsuga trees and large pines. Meilby et al.(2006) estimated that about 50 plots in Lete would lead to a precision of about $10 \%$ on basal area, and with 59 plots established this estimation was confirmed with a standard error of basal area of $11 \%$ of the mean.
Based on data from 2010, figure 2 and table 2 present height-diameter regressions for the most important tree species and the corresponding regression parameter estimates, respectively. Tree species were similar in Lete and Kunjo and there was almost no difference within species between diameter-height relationships in the two forests. Models were therefore prepared for the material as a whole. Compared to Tibrekot, the maximum height of trees in Lete, Kunjo and Kankali was considerably higher. In Kankali, the tallest tree species were Terminalia alata and Shorea robusta, in Lete and Kunjo, the tallest species were Tsuga dumosa, Abies sp. and Pinus wallichiana, and in Tibrekot the maximum height of Schima wallichii exceeded that of other species.

Figure 3 presents diameter distributions of trees in the four forests in 2010. In all forests the distributions were reverse J-shaped with low densities of large-diameter trees, and the density is therefore shown on a logarithmic scale. Lete was characterized by relatively high densities

Table 1: Results from permanent sample plots in $2010(n=240)$

\begin{tabular}{cccccccc}
\hline $\begin{array}{c}\text { Village / } \\
\text { forest }\end{array}$ & $\begin{array}{c}\text { Number } \\
\text { of plots }\end{array}$ & $\begin{array}{c}\text { Stem } \\
\text { number }\end{array}$ & DBH & Height & $\begin{array}{c}\text { Basal } \\
\text { area } \\
{\left[\mathbf{h a} \mathbf{H}^{-1}\right]}\end{array}$ & $\begin{array}{c}\text { Standing } \\
\text { volume }\end{array}$ & $\begin{array}{c}\text { Periodic } \\
\text { ann. volume } \\
\text { increment }^{\dagger} \\
{\left[\mathbf{m}^{3} \mathbf{h a}^{-1} \mathbf{y r} \mathbf{r}^{-1}\right]}\end{array}$ \\
\hline Lete & 59 & 821 & 24.6 & 12.9 & 31.8 & 274 & 3.9 \\
Kunjo & 63 & 662 & 28.6 & 16.8 & 32.9 & 311 & 4.9 \\
Tibrekot & 52 & 1170 & 19.5 & 11.0 & 28.8 & 178 & 2.5 \\
Kankali & 66 & 2110 & 12.0 & 8.4 & 20.0 & 134 & 7.6 \\
\hline
\end{tabular}

${ }^{\dagger} \mathrm{NB}$ : estimates include recruitment of trees that were previously too small, but trees that were felled between 2005 and 2010 are not considered as the year of felling is unknown. Estimates are thus likely to be conservative.
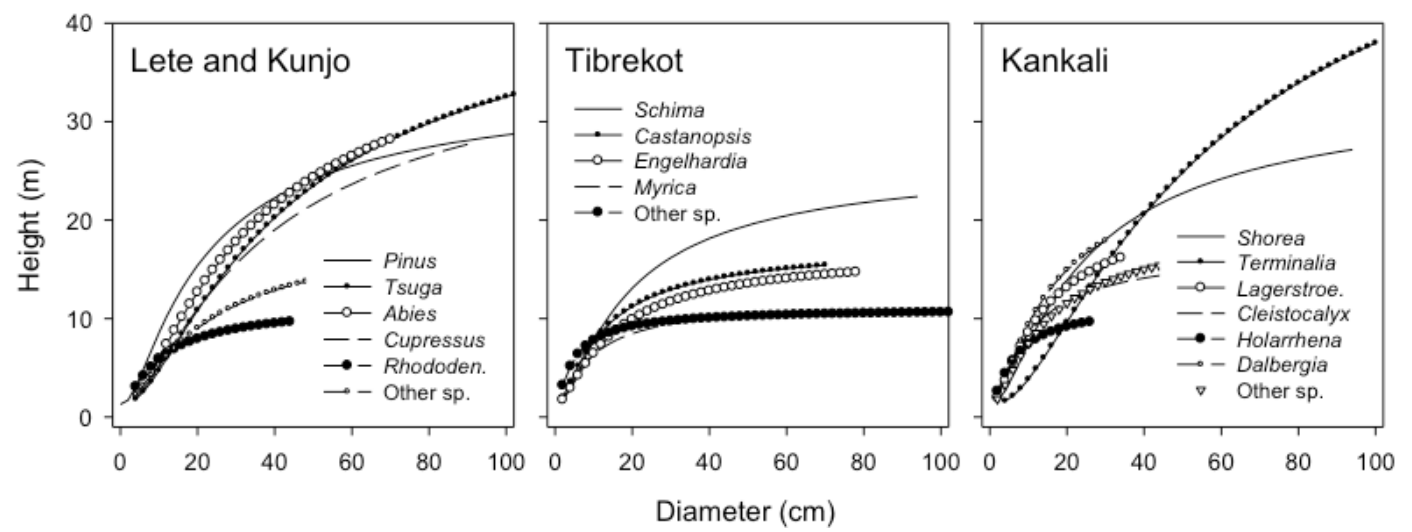

Fig. 2: Height-diameter regressions for the most important tree species found in the permanent sample plots in the three physiographic regions $(n=1146$, measurements conducted in 2010) 
Table 2. Regressions of tree height ( $h$, metres) on diameter (d, centimetres): $h=1.3+(d /$ [a $\left.\left.+b^{*} d\right]\right)^{3}$, where $a$ and $b$ are parameters to be estimated $(n=1146$, measurements conducted in 2010)

\section{Parameter estimates Model statistics}

\begin{tabular}{|c|c|c|c|c|c|c|c|c|}
\hline Site & Species & $\mathbf{a}$ & SE(a) & b & SE(b) & $\mathbf{n}$ & RMSE & $\mathbf{R}^{2}$ \\
\hline \multicolumn{9}{|c|}{ Kankali } \\
\hline & Shorea & 2.226 & 0.255 & 0.312 & 0.008 & 85 & 5.15 & 0.924 \\
\hline & Lagerstroemia & 1.505 & 0.468 & 0.364 & 0.033 & 31 & 3.16 & 0.921 \\
\hline & Terminalia & 5.410 & 1.346 & 0.245 & 0.025 & 17 & 5.83 & 0.922 \\
\hline & Cleistocalyx & 1.217 & 0.291 & 0.390 & 0.016 & 31 & 2.35 & 0.962 \\
\hline & Dalbergia & 1.586 & 0.509 & 0.345 & 0.030 & 11 & 2.56 & 0.968 \\
\hline & Holarrhena & 1.296 & 0.262 & 0.431 & 0.020 & 20 & 1.04 & 0.985 \\
\hline & Other species & 1.608 & 0.202 & 0.378 & 0.012 & 81 & 2.67 & 0.934 \\
\hline & All species & 2.443 & 0.127 & 0.314 & 0.005 & 276 & 4.08 & 0.917 \\
\hline \multicolumn{9}{|c|}{ Tibrekot } \\
\hline & Schima & 2.050 & 0.174 & 0.343 & 0.006 & 135 & 3.29 & 0.953 \\
\hline & Castanopsis & 1.611 & 0.212 & 0.389 & 0.011 & 105 & 2.86 & 0.933 \\
\hline & Engelhardia & 1.984 & 0.293 & 0.391 & 0.014 & 61 & 2.42 & 0.940 \\
\hline & Myrica & 1.310 & 0.337 & 0.457 & 0.018 & 47 & 1.79 & 0.955 \\
\hline & Other species & 0.595 & 0.447 & 0.483 & 0.035 & 23 & 2.83 & 0.899 \\
\hline & All species & 2.260 & 0.128 & 0.355 & 0.005 & 372 & 3.33 & 0.923 \\
\hline \multicolumn{9}{|c|}{ Lete and Kunjo } \\
\hline & Pinus & 2.219 & 0.141 & 0.307 & 0.004 & 251 & 4.36 & 0.950 \\
\hline & Tsuga & 3.849 & 0.588 & 0.279 & 0.010 & 39 & 6.37 & 0.936 \\
\hline & Cupressus & 3.236 & 0.548 & 0.307 & 0.012 & 43 & 4.75 & 0.931 \\
\hline & Abies & 3.336 & 0.628 & 0.288 & 0.018 & 33 & 4.82 & 0.927 \\
\hline & Rhododendron & 1.656 & 0.522 & 0.450 & 0.028 & 27 & 2.22 & 0.925 \\
\hline & Other species & 2.937 & 0.355 & 0.373 & 0.012 & 105 & 3.30 & 0.893 \\
\hline Lete & All species & 2.933 & 0.237 & 0.319 & 0.007 & 249 & 5.42 & 0.873 \\
\hline Kunjo & All species & 2.697 & 0.177 & 0.299 & 0.005 & 249 & 4.98 & 0.936 \\
\hline
\end{tabular}

for very small and very large trees, indicating that certain parts of the forest are regenerating (Strata 2 and 3 in Fig. 1) and other parts were highly stocked old-growth forest (Stratum 4 in Fig.1). In Kunjo medium-sized trees were relatively abundant while the number of small trees was not particularly high, indicating that most of the forest is either medium-aged or mature forest. In Tibrekot the diameter distribution is depicted as almost linear on the logarithmic density axis, except that there were still more large trees left than would be expected if the diameter distribution had been exponential. Finally, the forest in Kankali was clearly characterised by large densities of trees less than $20 \mathrm{~cm}$ in diameter.

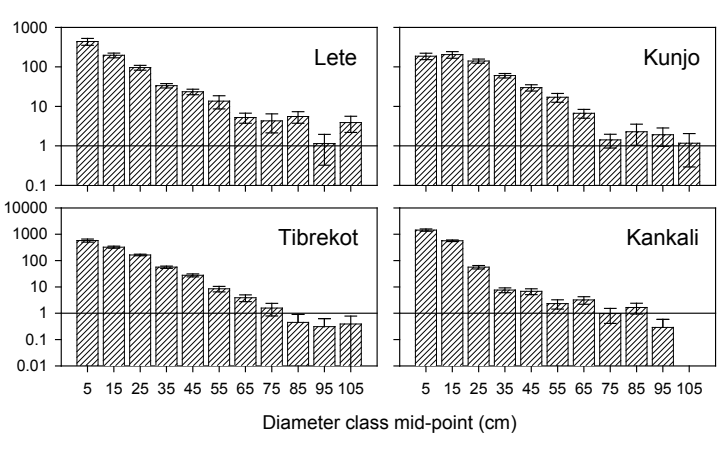

Fig. 3: Diameter distributions in 2010. Error bars indicate standard errors. Please note that vertical axes are logarithmic 
Figure 4 presents the standing volume of the four forests in 2010 , by species. As indicated above the forests of Lete and Kunjo were quite similar but the species composition was different. In Kunjo two-thirds $(65 \%)$ of the volume was contributed by $P$. wallichiana and most of the remaining one-third was distributed to T. dumosa (21\%) and Cupressus torulosa (7\%), but in Lete the contributions of Pinus (43\%) and Tsuga (35\%) were almost similar, Cupressus $(0.02 \%)$ was only found in a single plot, and a large group of 'other' species contributed about one-sixth of the total volume. In Tibrekot two-thirds of the volume was contributed by S. wallichii (65\%) and most of the remaining volume was contributed by the other dominant species, Castanopsis indica (23\%). The forest of Kankali was dominated by S. robusta, the volume of which constituted as much as $74 \%$ of the total standing stock.

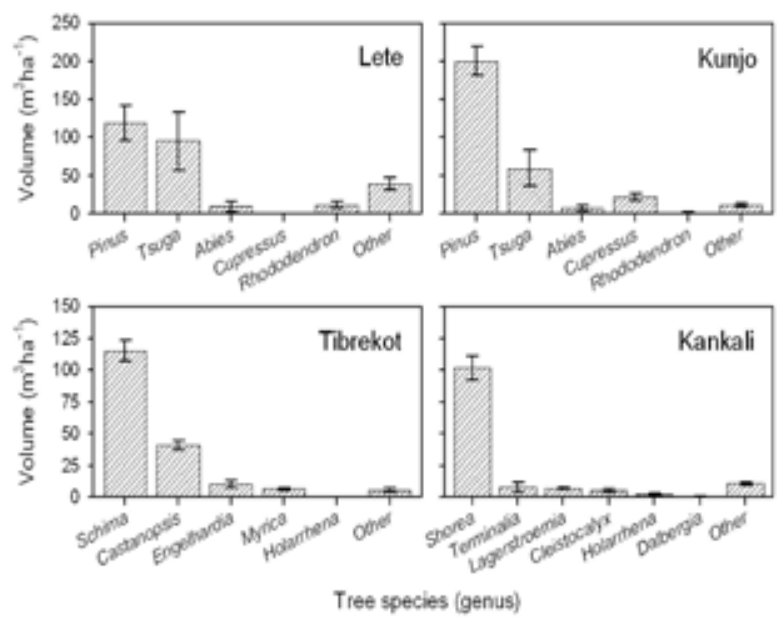

Fig. 4: Standing volume by species in 2010, error bars indicate standard errors

Figure 5 presents the distribution of volume to diameter classes for each forest. In Lete, very few large trees contributed a large proportion of total volume, and the remaining volume was distributed evenly to almost all other diameter classes. In Kunjo most of the volume was concentrated in diameter classes from $20-60 \mathrm{~cm}$, in Tibrekot there was little volume outside the diameter classes from 10-50 cm and in Kankali more than one-third of the volume was concentrated in the diameter class $10-20 \mathrm{~cm}$, and two-thirds of the volume was found in diameter classes below $30 \mathrm{~cm}$.

Figure 6 presents the distribution of volume increment from 2005 to 2010 to the most important species. In Lete the majority of the increment was contributed by $P$. wallichiana $(70 \%)$, followed by T. dumosa (24\%) and Rhododendron sp. (5\%).

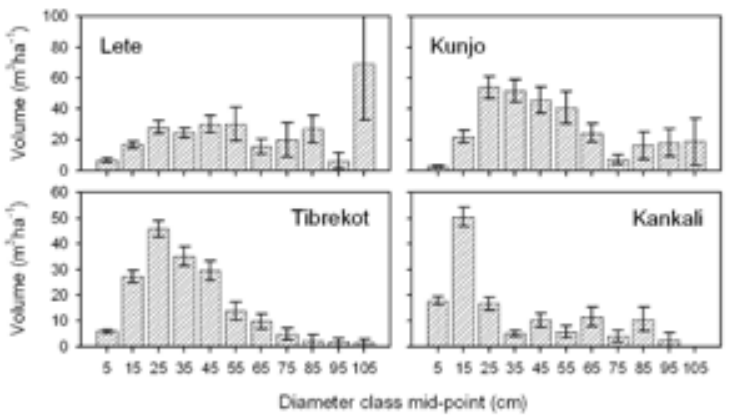

Fig. 5: Distribution of standing volume (2010) to diameter classes, error bars indicate standard errors

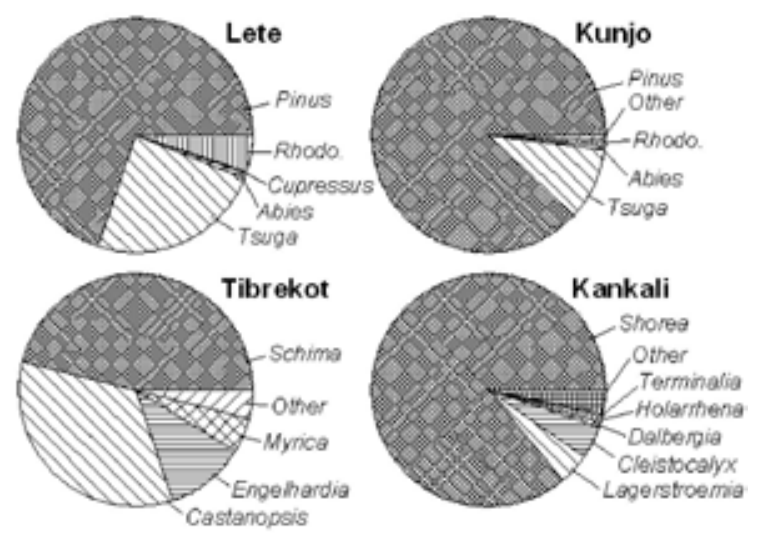

Fig. 6: Distribution of periodic annual volume increment (2005-2010) to species (see also Table 1)

In Kunjo Pinus contributed $88 \%$ and, collectively, the relative contribution of Pinus and Tsuga was $98 \%$ and thus even greater than in Lete. In Kankali the relative contribution of $S$. robusta $(86 \%)$ was as large as that of Pinus in Kunjo, and in Tibrekot increment was distributed more evenly with a bit less than half $(46 \%)$ to $S$. wallichii, one-third (34\%) to C. indica and one-tenth (11\%) to Engelhardia spicata.

Finally figure 7 shows the spatial distribution of the standing volume in the four forests in 2010. In Lete and Kunjo VDCs the volume surface was truncated at $700 \mathrm{~m}^{3} \mathrm{ha}^{-1}$ because estimates became unrealistically large in some parts of the forests. This was caused by only two plots that happened to include a few very large ( $>100 \mathrm{~cm} \mathrm{DBH}) T s u g a$ trees, leading to volume estimates of 1220 and $1460 \mathrm{~m}^{3} \mathrm{ha}^{-1}$ for these plots, thus forcing up the volume surface in the surrounding area. 


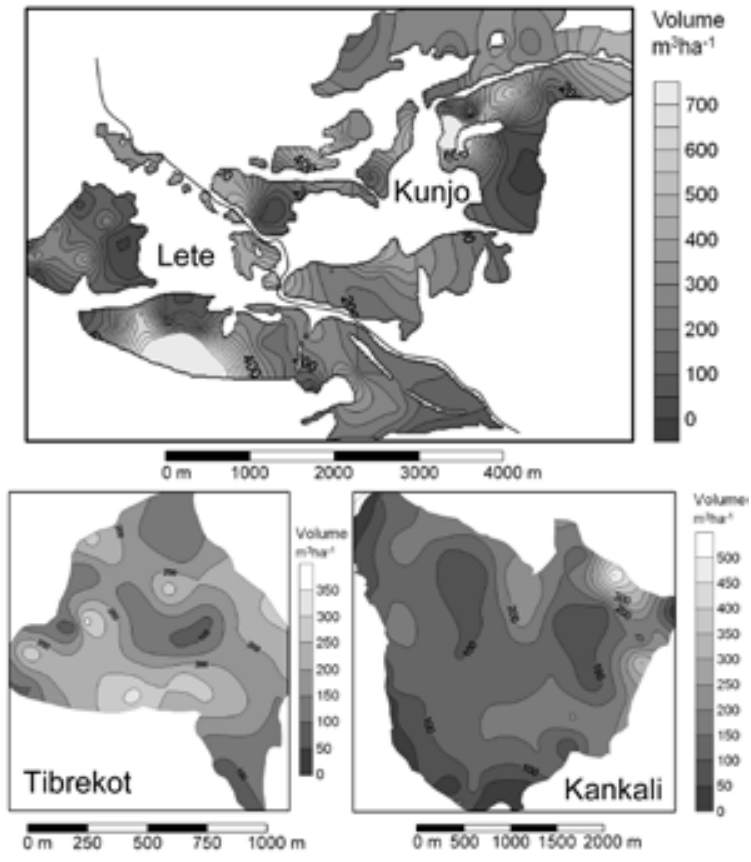

Fig.7: Interpolated spatial distribution of standing volume in the forests, 2010

In Lete the largest volumes were found at some distance south of the village. In Kunjo the pattern was less clear with patches of dense forest close to some populated areas and open forest close to others. In Tibrekot the largest volumes were mainly found in the younger forest stratum in the southwest and on the slopes to the northeast, and in Kankali the largest volumes were found at the centre and in the north, while a Dalbergia sissoo plantation and patches with Maoist encampments along the edge of the forest have been cleared or have low remaining volumes.

A preliminary evaluation of the data from the permanent sample plots shows that all four forests have large densities in the lowest diameter intervals, indicating good regeneration of trees. The species-level volume estimates illustrate that the dominant species are the ones expected for the respective zones.

Volume to diameter distributions show that there are relatively many large old trees in Mustang, while stands in the Middle Hills and Lowlands are presently (2010) dominated by younger trees. Forests in the mountains of Mustang were at the time of measurement not connected to the road network, and this may be one of the reasons why large old trees are still present there. Another reason could be the difficulties of timber harvest in the topographically challenging area. In Kankali the predominance of young trees is explained by the fact that the area handed over for community forestry in 1995 was quite degraded; therefore it is now being protected for regeneration.

Biomass accumulation is not entirely dependent on distance to settlement. The expected pattern of less accumulation close to settlement was found in some patches in Lete and Kunjo, whereas in Kankali the forest area closest to the settlement is being protected while regenerating. Different patterns of utilization also emerged from the sites. In Lete and Kunjo the biomass was distributed across diameter classes, meaning that forest management can include timber harvest in the near future. In Tibrekot and Kankali the predominance of biomass in the smaller diameter classes indicated that the forests need some time for regrowth before significant amounts of timber will be available. Large tracts in Kankali are dedicated to the regeneration of forest from barren hill (Stratum 2 in Fig.1), while in Tibrekot regeneration needs to take place within the standing forest.

Based on the pilot survey conducted in 2005, the stratification of the four forests and the allocation of plots to the strata shown in figure 1 constitute compromises that, with available resources, were intended to enable complete coverage of the forests, and to the extent possible minimize standard errors of standing stock and extraction measures. That a compromise is seen from the fact that minimization of standard errors of standing stock measures would often imply allocating most of the effort to areas quite far from villages, while minimization of the standard error of, e.g., subsistence firewood extraction would imply that most plots should be located close to villages. In Lete and Kunjo the survey did not include areas at elevations exceeding 3000 masl, thus leaving out forests at the tree line, and in Tibrekot an area on a steep slope (cliff) to the north-east was omitted as it was deemed inaccessible. Furthermore, in Lete and Kunjo it turned out that the strata surveyed in 2005 (Meilby et al. 2006) had to be supplemented as it emerged that certain patches of forest, not mentioned during the first field visits, were actually managed and used by the villages. The resulting plot network offers good coverage of most parts of the forests and should be useful for many types of forest-level studies. But for studies emphasizing particular forest types or individual species it may be necessary to supplement the existing network using temporary plots. 


\section{Additional data from permanent plots/sites}

A number of studies have already made use of the plot network. Additional data collected in the permanent sample plots include a one-year litter survey with traps in Kankali (2007/08), a shrub and herb species survey $(2006 / 07)$, a survey of fungi in Mustang (2005/06), a soil survey (2007), a survey of edible mushrooms in Tibrekot (2005), and repeated deadwood surveys in Mustang (2005/06 and 2010). In addition, in the forests but outside the permanent plots, above-ground biomass measurements were done for Shorea in Kankali (2007), and work of the same type was recently completed for Schima and Castanopsis in Tibrekot (2011), and in Mustang a B. Sc. thesis was prepared on the population structure of Taxus baccata subsp. wallichiana (Jensen, 2007). Furthermore, the permanent plots in Mustang formed the partial basis for two $\mathrm{PhD}$ theses (Christensen, 2008, and Rayamajhi, 2009), and M. Sc. thesis work was carried out on growth of $P$. wallichiana (Wagle, 2007; Wagle and Sharma 2011, 2012) and S. robusta (Sapkota 2008, Sapkota and Meilby, 2009), biomass of Hippophae salicifolia (Rajchal, 2007), and on the relationship between climate and the growth of $P$. wallichiana (Shrestha, 2012). Finally, outside the forests of Tibrekot and Kankali surveys of trees on farmland were conducted in 2009. The data from the permanent plots rests with the Institute of Forestry Pokhara and may serve as baseline data for future work, as teaching material and as the basis for information to the forest user groups for their planning.

\section{Conclusion}

Data from permanent sample plots in four forests of three research sites from three physiographic regions of Nepal have been analysed. Results include standing volume and periodic mean annual increment. In two forests stocking is presently (2010) very good; in the other two forests regrowth is required. The permanent sample plots have already been used for a range of different research studies and may serve as a baseline for future work.

\section{Acknowledgements}

We owe thanks to the Forest User Groups that agreed to participate in this study and to the local community members who assisted the field data collection. Moreover this work was possible only through the hard and backbreaking work of IOF faculty and students. The Danish Ministry of Foreign Affairs provided funding - 104. DAN.8.L.716.

\section{References}

Adhikari, B. 2005. Poverty, property rights and collective action: understanding the distributive aspects of common property resource management. Environment and Development Economics 10: 7-31.

Chhetri, B.B.K. 2010. Livelihoods, Forests and Poverty in the Nepal Himalaya. PhD thesis. Faculty of Life Sciences, University of Copenhagen, Denmark.

Chhetri, R.B. 2006. From protection to poverty reduction: a review of forestry policies and practices in Nepal. Journal of Forest and Livelihood 5: 66-77.

Christensen, M. 2008. Interaction between Humans and Biodiversity in Nepal's forest. PhD Dissertation, Faculty of Life Sciences, University of Copenhagen, Denmark.

Jensen, L.P. 2007. Population Structure, Regeneration and Utilisation of Himalayan Yew, Taxus baccata subsp. wallichiana - a Vulnerable Conifer in Central Nepal. B. Sc. thesis, Faculty of Life Sciences, University of Copenhagen, Denmark.

Meilby, H., Puri, L., Christensen, M. and Rayamajhi, S. 2006. Planning a system of permanent sample plots for integrated longterm studies of community-based forest management. Banko Janakari 16 (2): 3-11.

MFSC.2000. Guideline for Inventory of Community Forests. Ministry of Forests and Soil Conservation, Department of Forests, Community and Private Forest Division, Kathmandu, Nepal.

Müller, W. G. 2001. Collecting Spatial Data: Optimum Design of Experiments for Random Fields. Heidelberg: Physica-Verlag.

Pandit, R. and Bevilacqua, E. 2011. Forest users and environmental impacts of community forestry in the hills of Nepal. Forest Policy and Economics 13: 345-352. 
Rajchal, R. 2007. Biomass Production of Seabuckthorn (Hippophae salicifolia) and its Role in Income Generation. M.Sc. thesis, Tribhuvan University, Institute of Forestry, Pokhara, Nepal.

Rayamajhi, S. 2009. Forest Dependency, Livelihoods and Conservation of High Altitude Forests in Nepal. PhD Dissertation, Faculty of Life Sciences, University of Copenhagen, Denmark.

Sapkota, P. 2008. Growth of Sal (Shorea robusta Gaertn. f.) and its Economic Potential in Community Forest. M. Sc. thesis, Faculty of Life Sciences, University of Copenhagen, Denmark.

Sapkota, P. and Meilby, H. 2009. Modelling the growth of Shorea robusta using growth ring measurements. Banko Janakari 19 (2): 25-32.

Sharma, E.R. and Pukkala, T. 1990. Volume Tables for Forest Trees of Nepal. Publication no. 48. Ministry of Forests and Soil Conservation, Forest Survey and Statistics Division, HMG/ Nepal.
Shrestha, N.M. 2012. Response of Pinus wallichiana Tree Ring to Climate Variability in Mustang, Nepal. M. Sc. thesis, Tribhuvan University, Institute of Forestry, Pokhara, Nepal.

Wagle, B.H. 2007. Growth of Blue Pine in Lete and Kunjo of Mustang District. M. Sc. thesis, Tribhuvan University, Institute of Forestry, Pokhara, Nepal.

Wagle, B. H. and Sharma, R.P. 2011. Modelling height diameter relationship for Pinus wallichiana Trees for Lete and Kunjo of Mustang district. Banko Janakari 21 (2): 13-23.

Wagle, B. H and Sharma, R.P. 2012. Modelling individual tree basal area growth of Blue pine (Pinus wallichiana) for Mustang District in Nepal. Forest Science and Technology 8 (1): 21-27. 